\title{
ACESSIBILIDADE NAS CABINES DE PASSAGEIROS DE AERONAVES DE VOOS COMERCIAIS: UM OLHAR DO DESIGN CONSIDERANDO OS USUÁRIOS COM MOBILIDADE REDUZIDA
}

\section{ACCESSIBILITY INSIDE PASSENGER CABINS OF COMMERCIAL FLIGHT AIRCRAFTS: A DESIGN VISION CONSIDERING USERS WITH REDUCED MOBILITY}

\author{
Sílvia de Alencar Rennó ${ }^{1}$, M.Sc. \\ silvia.renno@uemg.br e https://orcid.org/0000-0003-1636-4127 \\ Iara Sousa Castro ${ }^{1}, \mathrm{PhD}$. \\ iara.castro@uemg.br e https://orcid.org/0000-0002-4819-7194 \\ Gabriela Leisa de Brito ${ }^{1}$, Bach. \\ gabrielaleisab@gmail.com
}

\footnotetext{
${ }^{1}$ Centro de Pesquisa e Desenvolvimento em Design e Ergonomia, Escola de Design, Universidade do Estado de Minas Gerais - UEMG, Belo Horizonte, MG, Brasil
}

Acessibilidade, Aeronaves Comerciais, Mobilidade Reduzida, Design Este estudo investiga, sob a ótica do design de ambientes e ergonomia, a importância da acessibilidade nas cabines de aeronaves de voos comerciais para a experiência de passageiros com mobilidade reduzida. A metodologia, de natureza qualitativa e quantitativa, inicia-se com uma revisão bibliográfica e desenvolve-se por meio de dois instrumentos de pesquisa com seus respectivos resultados apresentados: (1) questionários online para verificar as principais dificuldades enfrentadas pelos passageiros relativas ao espaço das aeronaves; (2) entrevistas semiestruturadas com passageiros que apresentam características de mobilidade reduzida. Os resultados da investigação apontam as principais dificuldades enfrentadas pelos passageiros nos interiores das cabines de aeronaves de voos comerciais e pretendem promover uma reflexão sobre as condições do ambiente de estudo, considerando as experiências dos passageiros em situações já existentes, de forma a contribuir para o desenvolvimento de projetos de aeronaves mais acessíveis e inclusivos.

\section{Accessibility, Commercial Aircraft, Reduced Mobility, Design}

From the perspective of interior design and ergonomics, this study investigates the importance of accessibility inside the cabins of commercial aircrafts for the experience of passengers with reduced mobility. The methodology, of qualitative and quantitative nature, begins with a bibliographic review and is developed through two research instruments with their respective results presented: (1) online questionnaires to verify the main difficulties faced by passengers regarding aircraft space; (2) semi-sctructured interviews with passengers with reduced mobility. Research results point out the main difficulties faced by passengers inside the cabins of commercial flights aircraft and intend to promote a thinking about the studied environment conditions, considering the passengers' experiences in existing situations, in order to contribute to the development of more accessible and inclusive aircraft projects. 


\section{Introdução}

A dificuldade na acessibilidade é um problema enfrentado pelos usuários do transporte aéreo comercial, especialmente aqueles que apresentam mobilidade reduzida. Isso compromete a sensação de conforto, autonomia e segurança para a realização de atividades comuns no interior das cabines durante as viagens, afetando os comportamentos destes usuários e limitando suas ações. Questiona-se, assim, qual o impacto da configuração do ambiente, relativa à acessibilidade, na experiência de viagem destes passageiros.

Este artigo propõe identificar as principais dificuldades enfrentadas pelos passageiros nos espaços internos de aeronaves comerciais para contribuir com projetos que promovam um design universal, concentrando sua abordagem na acessibilidade física. Pretende-se promover uma reflexão sobre as condições do ambiente de estudo a partir das experiências relatadas pelos usuários.

Para isso, realizou-se uma investigação considerando pessoas com mobilidade reduzida por representarem expressiva parcela da população brasileira (IBGE, 2010; IBGE, 2018; CASTILHO; MACIEL, 2018) e de usuários do transporte aéreo comercial (MINOZZO; MARGHANI, 2016; SOUZA, 2014). Considera-se que a discussão sobre suas demandas também beneficiaria outros passageiros que não apresentam dificuldades em mobilidade. Ressalta-se que, apesar de pertencerem ao grupo de pessoas com mobilidade reduzida, os cadeirantes não são contemplados neste estudo, cuja especificidade pelo uso da cadeira de rodas foi oportunizada em outro trabalho.

\section{Indivíduos com mobilidade reduzida e a importância da acessibilidade e do Design Universal}

Conforme Decreto ${ }^{0} 5.296$ (BRASIL, 2019a), indivíduos com mobilidade reduzida são aqueles que possuem dificuldade em movimentar-se temporária ou permanentemente, não necessariamente com deficiência física, e que tenham prejudicadas e reduzidas sua coordenação motora, mobilidade, flexibilidade e percepção. Diferentemente de deficiência, cuja definição também engloba limitações ou incapacidades visuais, auditivas e mentais (BRASIL, 2019a; BRASIL, 2019b), incluem-se no grupo de mobilidade reduzida, conforme Lei $\mathrm{n}^{\circ} 10.098$ (BRASIL, 2019b), pessoas com obesidade, idade igual ou superior a 60 anos, com criança de colo, gestantes e lactantes.

Pesquisas do Instituto Brasileiro de Geografia e Estatística (IBGE) e do Ministério da Saúde apontam índices relacionados a parcelas da população brasileira que se enquadram nestas categorias. $\mathrm{O}$ último Censo do IBGE (2010) revelou que 23,9\% dos brasileiros apresentavam algum tipo de deficiência, sendo 7\% motora. Alguma deficiência acometia $67,7 \%$ das pessoas com mais de 65 anos, as quais representavam $7,4 \%$ da população total indicando que o índice de envelhecimento vêm aumentando. A perspectiva é de que essa crescente se mantenha, chegando a $13,5 \%$ de idosos em $2030^{1}$. A pesquisa Estatísticas do Registro Civil (IBGE, 2018) relata 2.899.851 nascimentos em 2018, e indicadores do Instituto ${ }^{2}$ apontam taxa de fecundidade de 1,77 filho por mulher naquele ano, dados que sugerem o número de gestantes, lactantes e pessoas com crianças de colo. Segundo estudo do Ministério da Saúde (CASTILHO; MACIEL, 2018), em 2017, 18,9\% dos brasileiros apresentavam obesidade, ou seja, índice de massa corporal (IMC) igual ou acima de $30 \mathrm{~kg} / \mathrm{m}^{2}$ (WHO, 2000).

Estes dados revelam que parte considerável da população brasileira apresenta mobilidade reduzida, daí a importância da acessibilidade como garantia dos direitos fundamentais de cada indivíduo. A liberdade de

\footnotetext{
1 Projeção do IBGE disponível em: <https://www.ibge.gov.br/apps/populacao/projecao/index.html>. Acesso em: 17 abr.2020.

2 Disponíveis em: <https://www.ibge.gov.br/indicadores.html>. Acesso em: 17abr.2020.

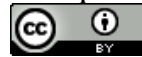


locomoção é direito universal de todos e a presença de obstáculos que dificultem ou impeçam os deslocamentos pode provocar desde prejuízos sociais a intelectuais (BRASIL, 2019a). A NBR 9050 (ABNT, 2020) define acessibilidade como

Possibilidade e condição de alcance, percepção e entendimento para utilização, com segurança e autonomia, de espaços, mobiliários, equipamentos urbanos, edifcações, transportes, informação e comunicação, inclusive seus sistemas e tecnologias, bem como outros serviços e instalações abertos ao público, de uso público ou privado de uso coletivo, tanto na zona urbana como na rural, por pessoa com defciência ou mobilidade reduzida. (ABNT, 2020, p.2).

Acessibilidade relaciona-se, portanto, à inclusão social ao promover a participação dos indivíduos na sociedade de maneira igualitária e isenta de discriminação. É uma forma de possibilitar que todos, e não somente aqueles com necessidades especiais, desempenhem atividades cotidianas com segurança (sem acidentes), autonomia (sem ajuda de terceiros) e conforto (MORAES, 2007).

Entendido como algo que vai além dos condicionantes térmicos, lumínicos e acústicos do ambiente, o conforto influencia substacialmente os estados afetivo e emocional das pessoas pois manifesta-se como sensação individual (SCHMID, 2018). Configura-se como importante critério de escolha de produtos e serviços, incluindo o transporte aéreo (ROSSI, 2011; SOUZA, 2010). Já a falta de autonomia, devido à ausência de acessibilidade em diferentes espaços e produtos, faz com que alguns indivíduos com mobilidade reduzida ou deficiência se isolem da sociedade e não usufruam do que desejam (OLIVEIRA; ROSA, 2018; SOUZA, 2014). A exclusão social de pessoas que demandam atendimentos especiais é um fenômeno enraizado na cultura de socialização desde os primórdios da humanidade, sendo os setores de esporte, cultura, lazer e transportes bastante carentes quanto à inclusão de todos, independentemente de suas capacidades físicas (MACIEL, 2000).

A aplicação dos conceitos e princípios do Design Universal em projetos de ambientes e produtos é uma forma de assegurar a inclusão de pessoas com necessidades especiais (CAMPESE, 2014; WANDERLEY et al, 2017) e contemplar a maioria dos usuários, de diferentes idades, classes, parâmetros antropométricos, gêneros, mobilidades reduzidas e com quaisquer deficiências que gerem limitações, ao considerar suas demandas específicas (OLIVEIRA; ROSA, 2018), promovendo acessibilidade. Elaborados por grupo multidisciplinar, estes princípios visam orientar processos de design e arquitetura, melhorar projetos existentes e conscientizar a sociedade sobre a utilização de produtos e espaços acessíveis, para que sejam atendidas as necessidades do maior número de usuários, isentando-os de riscos e desconfortos, e favorecendo experiências (THE CENTER FOR UNIVERSAL DESIGN, 1997).

\subsection{Passageiros com mobilidade reduzida no contexto da aviação comercial}

A aviação comercial, definida como "conjunto que inclui as técnicas e as ciências necessárias para a fabricação, manutenção e operação segura de aeronaves destinadas ao transporte de carga e/ou passageiros"3, integra o setor de aviação civil, regulamentado e fiscalizado, no Brasil, pela Agência Nacional de Aviação Civil (ANAC). O transporte aéreo público é definido como "transporte aéreo comercial (com fins lucrativos) de pessoas, de bens, e/ou de malas postais, regular ou não regular, doméstico ou internacional." (ANAC, 2020, p.21). Indicadores do Mercado de Transporte Aéreo da ANAC ${ }^{4}$ registram 119,4 milhões de passageiros pagos em 2019 (79,8\% em viagens domésticas e 20,2\% em internacionais), configurando aumento de 71,8\% em 10 anos. Considerado um dos tipos mais seguros, o transporte aéreo comercial tornouse mais democrático nos últimos anos devido, principalmente, ao surgimento das empresas de baixo custo e à

\footnotetext{
${ }^{3}$ Conforme ANAC, disponível em: <https://www2.anac.gov.br/anacpedia/por_esp/tr2137.htm> Acesso em: $19 \mathrm{abr} .2020$.

4 Disponíveis em: <https://www.anac.gov.br/assuntos/dados-e-estatisticas/mercado-de-transporte-aereo/consultainterativa/demanda-e-oferta-origem-destino $>$ Acesso em: 19abr.2020.
}

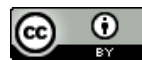


redução no preço das passagens, permitindo acesso a um maior número de usuários, dentre eles aqueles com mobilidade reduzida (CAMPESE, 2014; MINOZZO; MARGHANI, 2016; ROSSI, 2011; SOUZA, 2014).

Os voos de curta duração, sobretudo os domésticos, são realizados em aeronaves chamadas narrow body ${ }^{5}$ (de fuselagem estreita possuindo 1 corredor) que dispõem apenas da classe econômica. Voos mais longos são, normalmente, realizados em aeronaves wide body (de fuselagem larga com 2 corredores) e oferecem a primeira classe e executiva, além da econômica. $75 \%$ da frota brasileira são aeronaves com capacidade entre 51 e 200 passageiros, ou seja, do tipo narrow body (ANAC, 2019).

A infraestrutura de transportes coletivos deve garantir acessibilidade e inclusão de pessoas com deficiência ou com mobilidade reduzida (BRASIL, 2019a; BRASIL, 2019c) e a aviação comercial dispõe de uma legislação ainda superficial com esta finalidade. A NBR 14273 (ABNT, 1999) contempla passageiros com deficiência e os caracteriza como "Toda pessoa cuja mobilidade está reduzida, em virtude de uma incapacidade física - sensorial ou de locomoção - e que necessite de cuidados especiais no procedimento de embarque, desembarque ou durante o vôo." (ABNT, 1999, p.2). Entretanto, o conteúdo desta norma é predominantemente direcionado a usuários de cadeiras de rodas, o que acaba por desconsiderar as necessidades específicas de outros grupos não cadeirantes. Além disso, a regulamentação sobre o ambiente interno das aeronaves limita-se ao número de poltronas com braços escamoteáveis e a obrigatoriedade de lavatório acessível apenas em aeronaves de maior porte (wide body).

A ANAC, por meio da Resolução ${ }^{\circ} 280$ (ANAC, 2013), estabelece os procedimentos referentes à acessibilidade de Passageiro com Necessidade de Assistência Especial (PNAE), o qual ela define como

(...) pessoa com deficiência, pessoa com idade igual ou superior a 60 (sessenta) anos, gestante, lactante, pessoa acompanhada por criança de colo, pessoa com mobilidade reduzida ou qualquer pessoa que por alguma condição específica tenha limitação na sua autonomia como passageiro. (ANAC, 2013, p.1).

Esta Resolução prevê os serviços de assistência das companhias aéreas aos PNAEs e a infraestrutura disponibilizada pela administração dos aeroportos mas, referente aos espaços internos das aeronaves, regulamenta apenas: (1) devem existir assentos especiais (mas não define o que os caracteriza como) nas partes dianteira e traseira das aeronaves, exceto nas saídas de emergência; (2) número mínimo de assentos com descansos de braços móveis conforme capacidade da aeronave; (3) presença de uma cadeira de rodas de bordo em aeronaves com mais de 100 lugares; (4) fornecimento de sistemas de contenção para criança de colo e mecanismos de retenção adicional para os PNAEs que deles necessitem. Percebe-se, portanto, que o previsto nos regulamentos ainda é pouco para isentar os usuários de situações de desconforto, falta de autonomia e insegurança (SANTOS; FREITAS, 2014; SOUZA, 2014).

Considerando os expressivos números e a diversidade de usuários do transporte aéreo comercial, é imprescindível observar suas atividades e necessidades durante o voo (CAMPESE, 2014; ROSSI, 2011; SANTOS; FREITAS, 2014; SOUZA, 2014). Algumas pesquisas, nacionais e internacionais, discutem as condições de conforto das cabines de aeronaves, as principais atividades realizadas por passageiros durante os voos, o grau de importância de cada uma delas e as principais dificuldades enfrentadas, bem como questões dimensionais dos espaços e equipamentos nas aeronaves (CAMPESE, 2014; SOUZA, 2014). Mas ainda é necessário ampliar a compreensão das experiências de passageiros com mobilidade reduzida no interior das cabines, na realidade brasileira. Percebe-se, pelas regulamentações e pesquisas já realizadas (CAMPESE, 2014; ROSSI, 2011) que o tipo de aeronave, a classe e a duração do percurso de voo influenciam na configuração espacial e, consequentemente, na acessibilidade e sensação de conforto dos passageiros.

${ }^{5}$ Definições de narrow body e wide body em: https://www.anac.gov.br/assuntos/legislacao/legislacao-1/iac-e-is/is/is-129001/@@display-file/arquivo_norma/IS129-001B.pdf. 
Fabricantes e companhias aéreas procuram incrementar alguns serviços em suas aeronaves (ROSSI, 2011), mas, por falta de regulamentação específica, algumas decisões acabam conduzidas por questões comerciais e financeiras, prejudicando consideravelmente a acessibilidade, como nos espaços dedicados às poltronas (SANTOS; FREITAS, 2014).

Independente dos critérios específicos que determinam as dimensões de projeto do produto "poltrona" isoladamente, merece mais atenção o espaço onde a poltrona está instalada, pois, além dos critérios ergonômicos e as necessidades de espaço inerentes ao ato de sentar, além das mudanças de posição que a imobilidade forçada impõe, é preciso respeitar condições mínimas de acessibilidade, os limites de segurança e, sobretudo, é preciso oferecer conforto ao passageiro na maior etapa da sua viagem, quando ele está sentado em seu assento. (SANTOS; FREITAS, 2014, p. 34).

O Programa de Avaliação Dimensional criado pela ANAC em 2010, por meio da Resolução ${ }^{\circ} 135^{6}$, classifica os espaços das poltronas das aeronaves brasileiras de voos comerciais e estabelece que as companhias aéreas divulguem a etiqueta com classificação atribuída à aeronave. Contudo, tal medida é informativa (sobre as condições dos assentos ofertados) e não regulamentária. Salienta-se que atender as demandas específicas dos usuários, considerando o conforto, constitui-se importante fator de diferenciação competitiva de mercado (SOUZA, 2010).

Estudos recentes apontam que as necessidades dos passageiros têm sofrido mudanças, mostrando que os viajantes de amanhã vão demandar cada vez mais, altos níveis de controle, conforto, segurança e personalização da experiência da viagem. (SOUZA, 2010, p. 20).

Constata-se que os passageiros em geral e, especialmente, aqueles com mobilidade reduzida, experimentam situações adversas durante os voos (CAMPESE, 2014; MINOZZO; MARGHANI, 2016; SANTOS; FREITAS, 2014; SOUZA, 2014). Este estudo reconhece a complexidade dos projetos de aeronaves e a necessidade de um trabalho multidisciplinar, e acredita ser fundamental a escuta dos relatos dos passageiros e suas vivências para contribuir em futuros ajustes nas regulamentações específicas e proposições projetuais mais assertivas e eficazes quanto à acessibilidade e ao design universal.

o principal desafio do projeto de cabines de aeronaves é a integração de diferentes demandas em relação aos fatores humanos com outros requisitos do projeto, como viabilidade econômica, desempenho, resistência da aeronave, entre outros. (CAMPESE, 2014, p.38).

\section{Metodologia}

Esta pesquisa, de natureza qualitativa e quantitativa, iniciou-se com uma revisão bibliográfica de publicações científicas, normas e leis referentes à acessibilidade, design universal, transporte aéreo comercial e passageiros com mobilidade reduzida. Para verificar a discussão proposta em uma realidade encontrada, utilizaram-se instrumentos de pesquisa que permitiram traçar um diagnóstico da experiência dos usuários com o ambiente de estudo.

Um questionário online foi elaborado objetivando verificar se o transporte aéreo é meio muito utilizado pela população, a porcentagem de passageiros com mobilidade reduzida e as principais dificuldades enfrentadas pelos usuários relativas ao espaço das aeronaves. As perguntas foram formuladas baseadas em dados e informações obtidos na revisão bibliográfica e consideraram atividades corriqueiras dos passageiros durante

6 Disponível em: https://www.anac.gov.br/assuntos/legislacao/legislacao-1/resolucoes/resolucoes-2010/resolucao-no135-de-09-03-2010. Acesso em: 19abr.2020. 
o voo, por eles sinalizadas em graus de dificuldade. Nesta etapa, não se restringiu as respostas aos usuários com mobilidade reduzida, possibilitando um comparativo entre as respostas de pessoas com diferentes demandas. Os resultados obtidos auxiliaram na elaboração das entrevistas semiestruturadas.

As entrevistas semiestruturadas foram realizadas com 18 pessoas que viajaram em aeronaves comerciais nos últimos três anos na condição de passageiro com mobilidade reduzida. As perguntas abordaram aspectos gerais de uso dos espaços e equipamentos das aeronaves. Não foi determinado um modelo de aeronave ou companhia aérea, considerando-se as similaridades das situações encontradas, ainda que haja pequenas customizações. Os entrevistados caracterizaram a aeronave pela sua capacidade (configuração de poltronas e número de corredores), duração do voo e classe de viagem. Estas informações foram importantes para compreender a sensação de conforto e acessibilidade nas diferentes configurações espaciais. Ainda que houvesse um pré-roteiro, as entrevistas possibilitaram relatos espontâneos das experiências de viagens dos participantes, enriquecendo substancialmente os dados da pesquisa.

Os resultados obtidos com a aplicação dos instrumentos técnicos foram quantificados e apresentados em gráficos.

Considera-se extremamente relevante para este trabalho a interlocução com os passageiros com mobilidade reduzida, pois entende-se que o conforto é expresso por uma conjuntura emocional e portanto, particular e situacional (SCHMID, 2018), em que as condições de acessibilidade são preponderantes, principalmente para este grupo de usuários.

\section{Investigação sobre as experiências dos passageiros}

O referencial teórico revelou dados que levaram a uma investigação sobre as experiências dos passageiros em aeronaves de voos comerciais, visando diagnosticar as condições de acessibilidade no ambiente de estudo, composta por dois instrumentos de pesquisa (questionário online; entrevista semiestruturada) cujos resultados serão apresentados a seguir.

\subsection{Resultados do questionário online}

O questionário online, elaborado na plataforma Google Formulários e veiculado em redes sociais, obteve 274 respostas em âmbito nacional. Na sequência do questionário, participaram aqueles que responderam já terem viajado em aeronaves comerciais (214 pessoas ou 78,1\% do total). Destes, 103 realizaram apenas viagens de curta duração (até 5 horas), 14 fizeram voos de longa duração (acima de 5 horas) e 97 utilizaram ambas situações. Das 214 pessoas, 58 (27,1\%) declararam apresentar algum tipo de mobilidade reduzida (FIG.1).
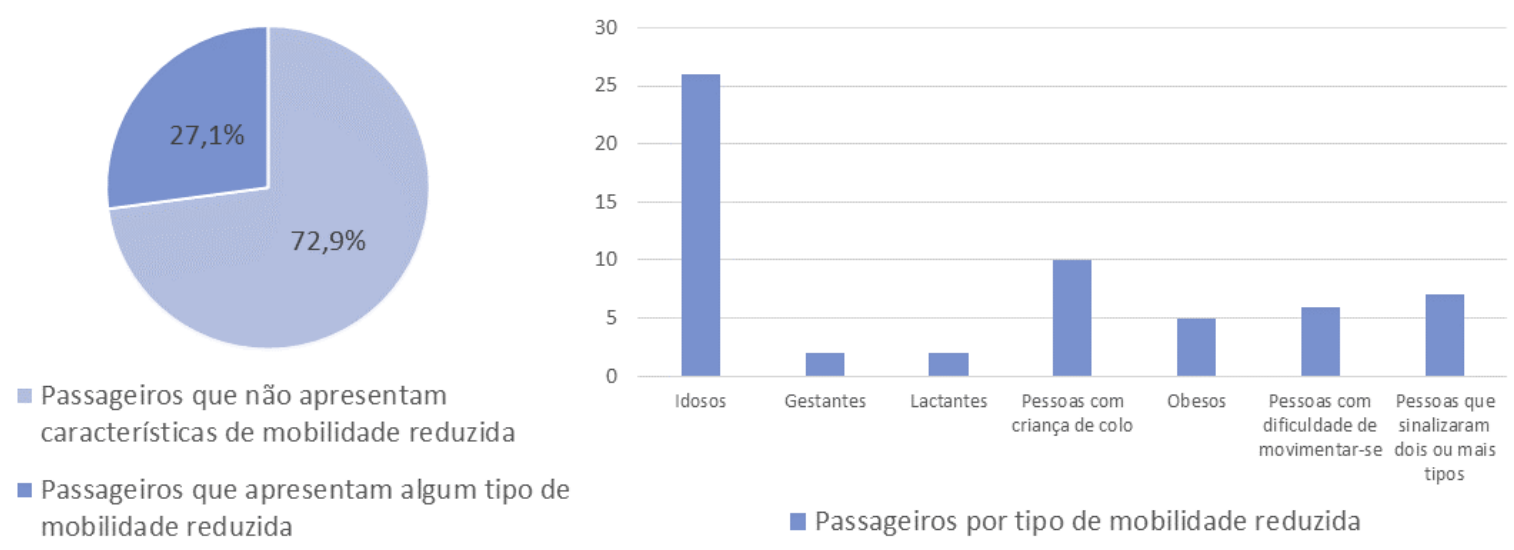

Figura 1: Características dos respondentes relativas à mobilidade reduzida. 
Fonte: As autoras.

Com relação às atividades avaliadas pelos participantes, tanto os que se declararam com mobilidade reduzida quanto aqueles que não a apresentam, as com menores graus de dificuldade foram o uso do cinto de segurança e o manuseio da bandeja de alimentação, seguidas dos ajustes de inclinação das poltronas e acionamento dos controles. A principal queixa identificada foi referente a movimentar-se enquanto a poltrona da frente estiver inclinada, cujas respostas em níveis de muita ou extrema dificuldade superaram as de nenhuma ou pouca. A maioria das respostas encontra-se em grau de pouca dificuldade. Entretanto, são expressivos os números que apontam muita ou extrema dificuldade, sobretudo nas atividades de sentar-se em poltronas que não estejam nos corredores, acomodar as pernas nos espaços disponíveis e dividir o apoio de braços com o passageiro ao lado. (GRAF.1 e GRAF.2)

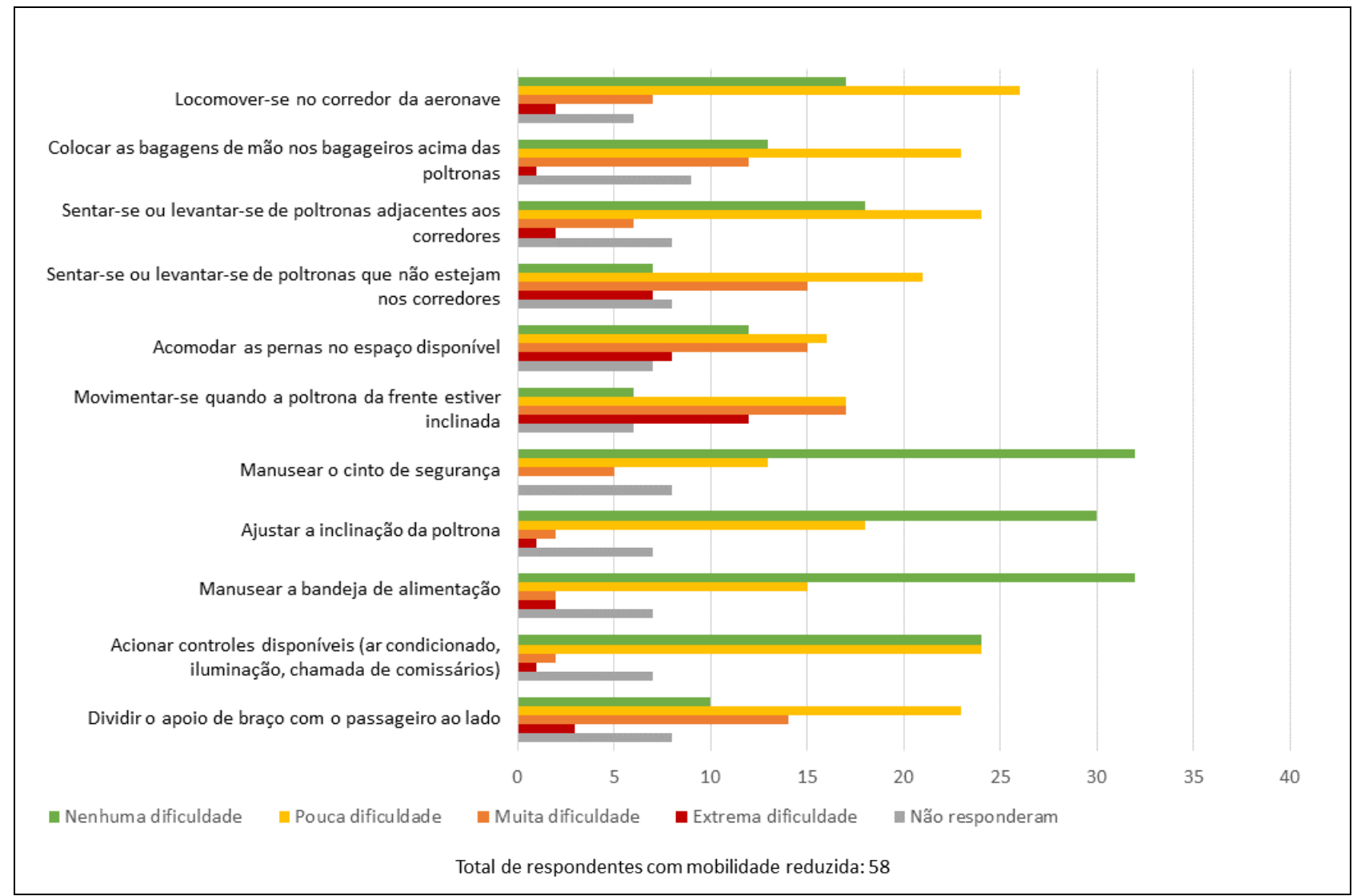

Gráfico 1: Avaliação dos respondentes com mobilidade reduzida de atividades no interior das cabines. Fonte: As autoras. 


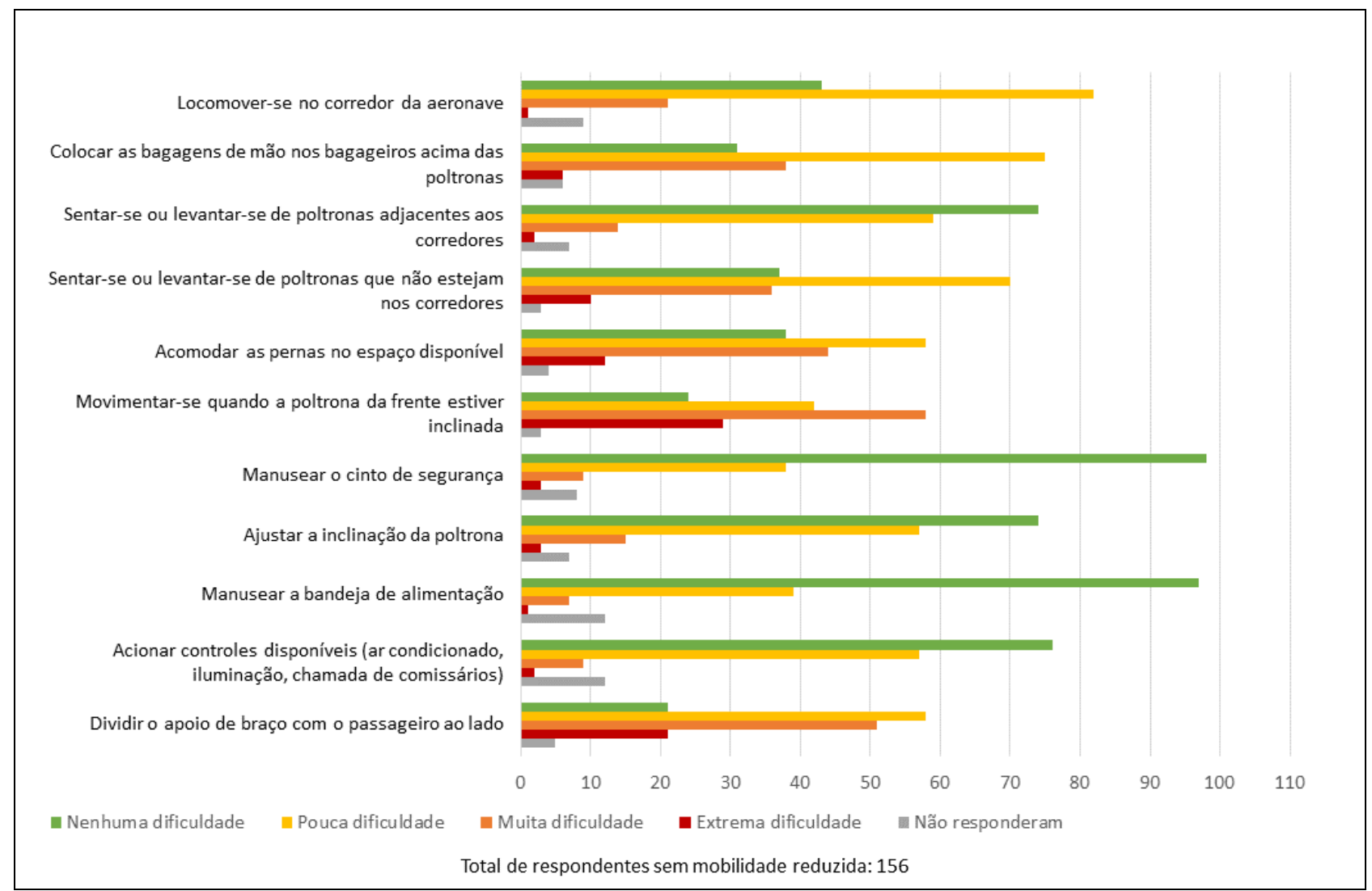

Gráfico 2: Avaliação dos respondentes sem mobilidade reduzida de atividades no interior das cabines. Fonte: As autoras.

Dos 214 passageiros participantes, 160 disseram terem utilizado os sanitários das aeronaves, sendo 43 destes com mobilidade reduzida. A atividade mais citada com algum nível de dificuldade foi a de movimentar-se no interior dos sanitários. Apenas 31 respondentes dos 160 alegaram nenhuma dificuldade nesta atividade. Em contrapartida, trancar a porta, acionar a descarga e utilizar elementos disponíveis nos sanitários foram as atividades menos expressivas quanto ao grau de dificuldade em desempenhá-las. Todos os passageiros com mobilidade reduzida que já precisaram utilizar o fraldário e o serviço de bordo nos sanitários relataram alguma dificuldade ao fazê-lo. (GRAF.3 e GRAF.4) 


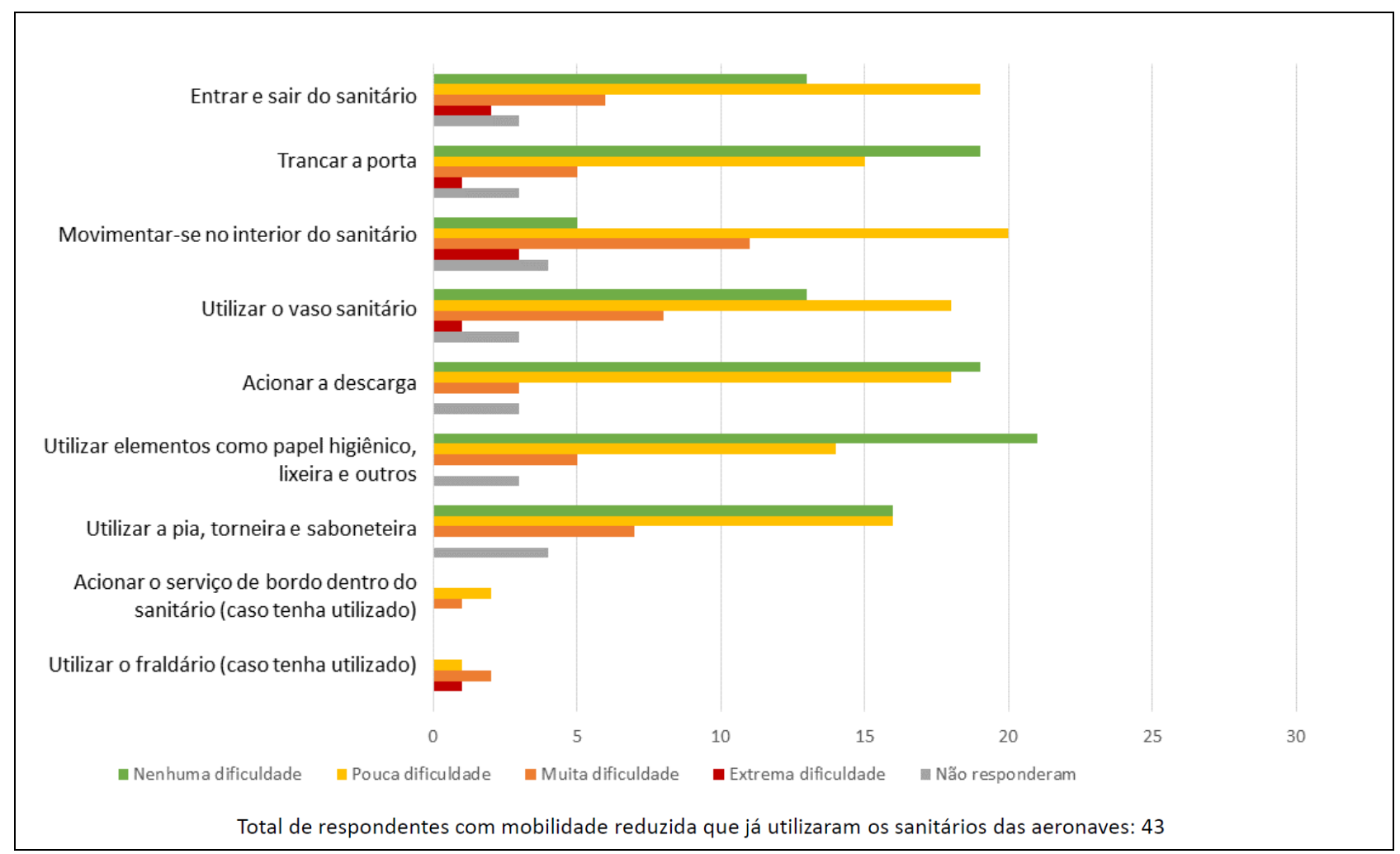

Gráfico 3: Avaliação dos respondentes com mobilidade reduzida de atividades realizadas no interior dos sanitários. Fonte: As autoras.

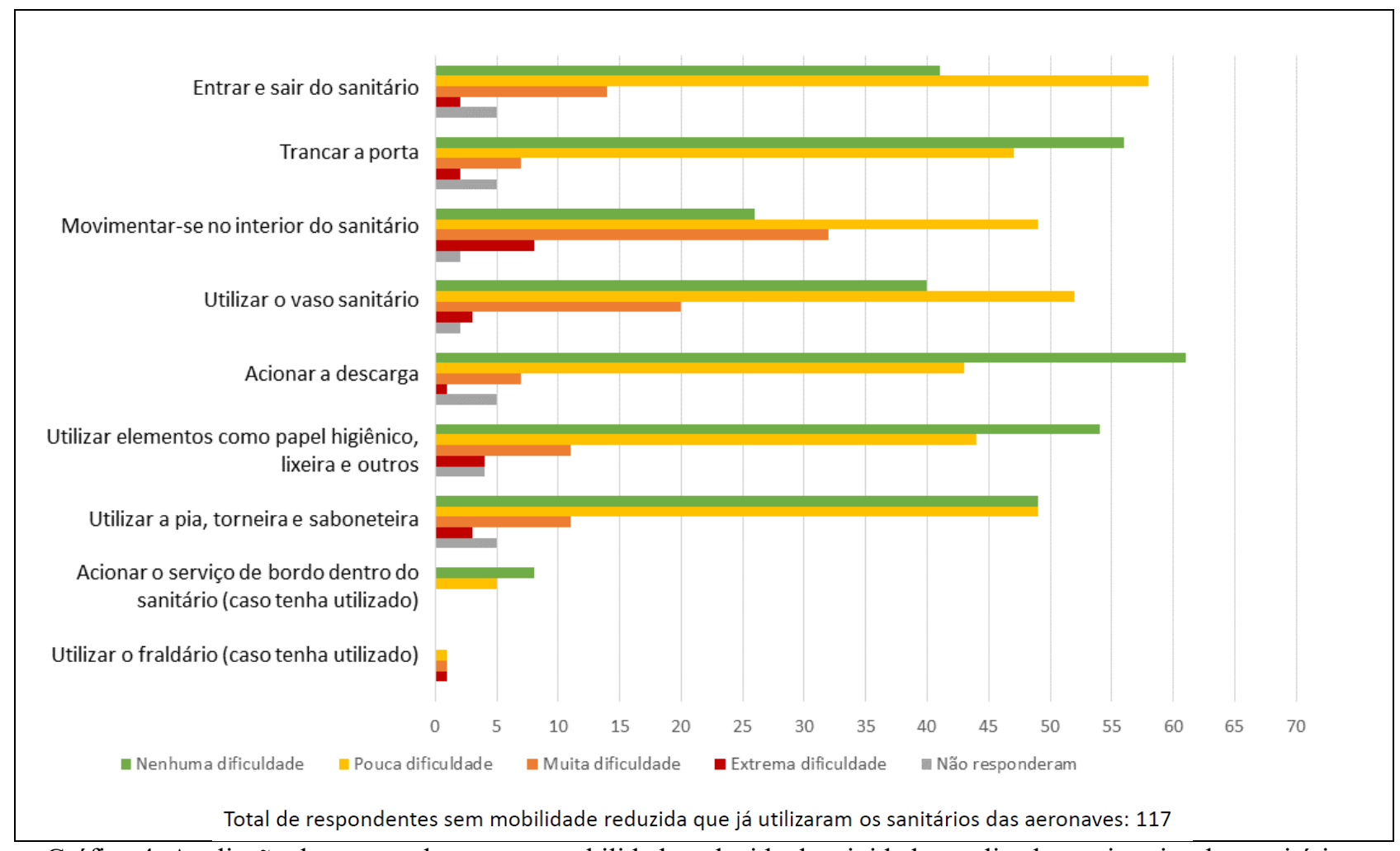

Gráfico 4: Avaliação dos respondentes sem mobilidade reduzida de atividades realizadas no interior dos sanitários. Fonte: As autoras. 
As respostas permitiram concluir que grande parcela dos participantes utilizam o transporte aéreo e, destes, mais de $1 / 4$ encontravam-se em condições de mobilidade reduzida. Ademais, as dificuldades enfrentadas por passageiros com e sem mobilidade reduzida são muito parecidas e concentram-se, majoritariamente, nas atividades relacionadas aos espaços de circulação e movimentação, e pouco referente ao uso dos equipamentos. As informações obtidas nos questionários justificaram a sequência da pesquisa.

\subsection{Resultados das entrevistas}

As entrevistas foram realizadas entre outubro/2019 e janeiro/2020, com 18 pessoas com diferentes características de mobilidade reduzida (FIG.2) que viajaram nos útimos três anos. Destas, 8 fizeram voos domésticos, de curta duração, em aeronaves narrow body; 2 fizeram viagens internacionais, de longa duração, em aviões wide body; e 8 utilizaram ambas modalidades. Apenas 3 entrevistados relataram viagens em classe executiva. As entrevistas foram aprovadas pelo Comitê de Ética em Pesquisa e os participantes assinaram Termo de Consentimento Livre e Esclarecido. Suas identidades foram mantidas totalmente em sigilo.

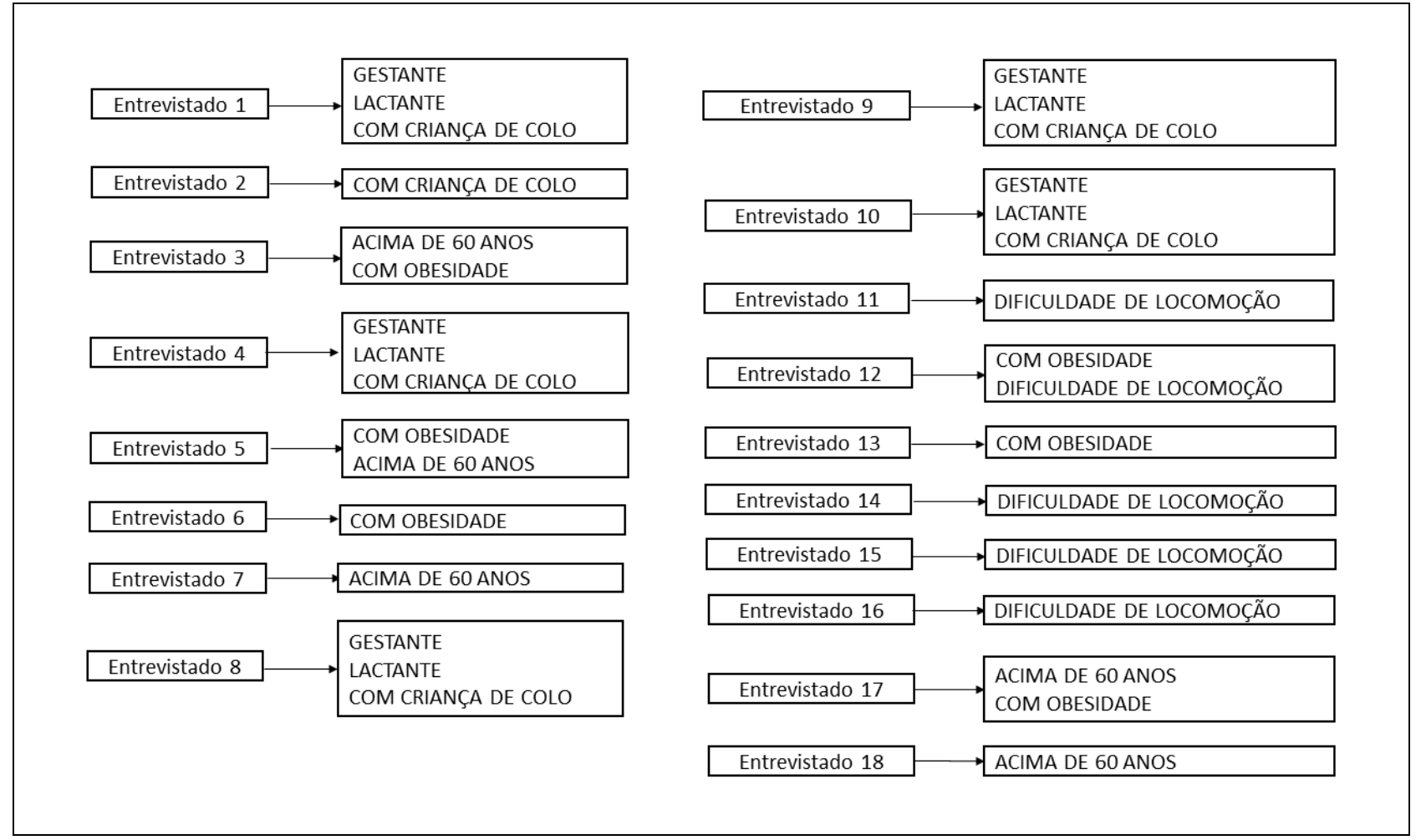

Figura 2: Características dos entrevistados quanto à mobilidade reduzida.

Fonte: As autoras.

As perguntas concentraram-se nas características físicas das aeronaves, como a disposição das poltronas, localização e estrutura dos sanitários e outros elementos importantes para a utilização do espaço. Todos os entrevistados, independente do tipo de mobilidade reduzida, relataram dificuldade na realização de alguma atividade. Um problema apontado pela grande maioria, principalmente por aqueles com alguma dificuldade de locomoção por acidente ou lesão, foi a ausência de apoios para as mãos ao longo da aeronave, reduzindo a sensação de segurança ao caminhar pelo corredor. Os idosos foram os que menos relataram dificuldades, pois disseram receber ajuda de acompanhantes ou da tripulação, principalmente para acomodar suas bagagens de mão. 
De maneira geral, as grávidas em estágio avançado de gestação e os obesos foram os que apontaram mais situações adversas, como acomodar-se nas poltronas em função do pequeno espaço entre as fileiras, principalmente quando a poltrona à frente encontra-se inclinada, e da largura do assento, causando constrangimento em relação ao passageiro ao lado. Por isso, muitos deles optam, quando possível, pelos assentos adjacentes aos corredores. O uso da bandeja de alimentação também torna-se mais complicado para estes grupos de usuários, assim como o uso do sanitário, em função de suas dimensões e acessos extremamente reduzidos. Entretanto, o cinto de segurança não foi sinalizado como problema, existindo extensores, caso necessário.

A necessidade de equipamentos de apoio foi a principal observação das passageiras lactantes e daqueles acompanhados por crianças de colo. Os apoios para os braços nas poltronas são essenciais no momento de amamentação e na sustentação das crianças, mas estes são compartilhados com os passageiros ao lado. Os berços, oferecidos por algumas companhias aéreas, foram citados como acessórios de grande ajuda, principalmente em viagens longas. Contudo, por segurança, seu uso é restrito aos momentos em que os avisos de atar cintos estão desligados. O espaço diminuto dos sanitários dificulta a utilização do fraldário. Alguns entrevistados consideraram o espaço suficiente para a troca de fraldas e apoio de objetos pessoais. Outros alertaram que o trocador depende do tamanho e peso da criança e, algumas vezes, não transmite segurança.

A estatura foi sinalizada por alguns entrevistados como característica importante para o conforto e realização de algumas atividades. Pessoas baixas sentiram dificuldades com o apoio dos pés no piso e com o acionamento dos comandos acima das poltronas, enquanto as mais altas relataram bastante desconforto com o espaço disponível para as pernas.

Apenas 3 entrevistadas (todas na condição de grávida, lactante e com criança de colo) relataram experiências em classe executiva de voos internacionais. A principal diferença apontada foi referente ao espaço dedicado às poltronas garantindo maior conforto. Entretanto, a estrutura dos sanitários é a mesma comparada à classe econômica.

Observou-se que a dificuldade para realização de atividades corriqueiras no interior das aeronaves aumenta quando o passageiro apresenta mais de uma característica de mobilidade reduzida (p.ex.: grávida com criança de colo, ou idoso e obeso). Nestes casos, o auxílio de outras pessoas torna-se fundamental. As entrevistas confirmaram os resultados obtidos nos questionários online e evidenciaram os pontos críticos dos ambientes internos das cabines de passageiros de aeronaves comerciais sob a perspectiva de passageiros com mobilidade reduzida.

\section{Discussão dos resultados}

A investigação sobre as experiências dos passageiros permitiu identificar pontos fundamentais no ambiente interno das aeronaves que comprometem consideravelmente a acessibilidade: ausência de apoios para as mãos ao longo da aeronave, apoios para os braços compartilhados nas poltronas, reduzido espaço pessoal na poltrona e espaço do sanitário. Isso indica que o principal problema encontra-se nos espaços livres, ou seja, no layout das aeronaves e na ausência de alguns equipamentos de apoio e não no design dos objetos e equipamentos em si.

Constatou-se que, nos quesitos pesquisados, não há diferenças significativas nas classes econômicas dos tipos de aeronaves narrow body e wide body, mas que na classe executiva é melhor a sensação de conforto e acessibilidade no que se refere ao espaço individual das poltronas. $\mathrm{O}$ tempo de viagem é fator importante pois influencia na realização e frequência de algumas atividades, como o uso dos sanitários, por exemplo. 
As dificuldades de acessibilidade criam situações adversas aos passageiros comprometendo suas experiências de voo. Constrangimentos das mais variadas dimensões, resultantes da enorme proximidade com os passageiros ao lado em função do pequeno espaço individual, e das áreas reduzidas para passagens, deslocamentos e movimentações, foram muito relatados. A privação de alguma atividade, pelas dificuldades impostas, também é consequência da falta de acessibilidade. Muitos passageiros evitam usar o sanitário ou sair de seus assentos durante o voo, o que pode causar, inclusive, problemas de saúde. Estas mesmas dificuldades também interferem nas escolhas pelos assentos, nem sempre os de preferência. Houve relatos de pessoas preocupadas com a viabilidade de realizar algumas viagens aéreas e que já reconsideraram voos internacionais longos. Tudo isso mostra o enorme impacto que a acessibilidade tem nas experiências dos passageiros do transporte aéreo comercial, especialmente os que encontram-se na condição de pessoas com mobilidade reduzida.

\section{Considerações finais}

Este artigo demonstrou que a dificuldade de acessibilidade pode comprometer as experiências dos passageiros no interior de aeronaves de voos comerciais e impactar profundamente na sensação de conforto, autonomia e segurança, sobretudo daqueles com mobilidade reduzida. Percebe-se que é preciso planejar os interiores das aeronaves não apenas segundo critérios técnicos, econômicos e comerciais, mas também considerando os aspectos humanos. Espera-se que este estudo fomente futuras investigações na área do transporte aéreo comercial ao evidenciar a importância de se considerar a perspectiva do usuário e suas demandas, resultando em projetos mais acessíveis e inclusivos.

\section{Referências Bibliográficas}

AGÊNCIA NACIONAL DE AVIAÇÃO CIVIL (ANAC). Anuário do Transporte Aéreo: Gráficos e Tabelas - 2018. Brasília: ANAC, 2019. Disponível em: <https://www.anac.gov.br/assuntos/dados-eestatisticas/mercado-de-transporte-aereo/anuario-do-transporte-aereo/anuario-do-transporte-aereo $>$. Acesso em: 19abr.2020.

\section{AGÊNCIA NACIONAL DE AVIAÇÃO CIVIL (ANAC). Regulamento Brasileiro da Aviação Civil no 1} emenda n6: Definições, regras de redação e unidades de medida para uso nos normativos da ANAC. Brasília: ANAC, 2020. Disponível em: $<$ https://www.anac.gov.br/assuntos/legislacao/legislacao-1/rbha-erbac/rbac>. Acesso em: 19abr.2020.

\section{AGÊNCIA NACIONAL DE AVIAÇÃO CIVIL (ANAC). Resolução n 280, de 11 de julho de 2013.}

Dispõe sobre os procedimentos relativos à acessibilidade de passageiros com necessidade de assistência especial ao transporte aéreo e dá outras providências. Brasília: ANAC, 2013. Disponível em:

$<$ https://www.anac.gov.br/assuntos/legislacao/legislacao-1/resolucoes/resolucoes-2013/resolucao-no-280-de11-07-2013>. Acesso em: 19abr.2020.

ASSOCIAÇÃO BRASILEIRA DE NORMAS TÉCNICAS (ABNT). NBR 9050: Acessibilidade a edificações, mobiliário, espaços e equipamentos urbanos. 4 ed. Rio de Janeiro, ABNT, 2020.

ASSOCIAÇÃO BRASILEIRA DE NORMAS TÉCNICAS (ABNT). NBR 14273: Acessibilidade da pessoa portadora de deficiência no transporte aéreo comercial. Rio de Janeiro, ABNT, 2009.

BRASIL. Decreto n ${ }^{0}$ 5.296, de 2 de dezembro de 2004. Regulamenta as Leis $N^{\circ} 10.048$ e 10.098. Brasília, DF: Presidência da República, [2019a]. Disponível em: <http://www.planalto.gov.br/ccivil_03/_ato20042006/2004/decreto/d5296.htm>. Acesso em: 17abr.2020. 
BRASIL. Lei $\mathbf{n}^{0} \mathbf{1 0 . 0 9 8}$, de 19 de dezembro de 2000. Estabelece normas gerais e critérios básicos para a promoção da acessibilidade das pessoas portadoras de deficiência ou com mobilidade reduzida, e dá outras providências. Brasília, DF: Presidência da República, [2019b]. Disponível em:

$<$ http://www.planalto.gov.br/ccivil_03/leis/L10098.htm>. Acesso em: 17abr.2020.

BRASIL. Lei no 13.146, de 06 de julho de 2015. Institui a Lei Brasileira de Inclusão da Pessoa com Deficiência (Estatuto da Pessoa com Deficiência). Brasília, DF: Presidência da República, [2019c]. Disponível em: <http://www.planalto.gov.br/ccivil_03/_ato2015-2018/2015/lei/113146.htm\#art127>. Acesso em: 17abr.2020.

CAMPESE, Carina. Cabine de aeronaves e tecnologia assistiva: contribuições de um estudo de prospecção. 2014. Dissertação (Mestrado em Engenharia de Produção) - Universidade Federal de São Carlos, São Carlos, 2014.

CASTILHO, Ingrid; MACIEL, Victor. Com obesidade em alta, pesquisa mostra brasileiros iniciando vida mais saudável. Ministério da Saúde, Brasília, 18 jun. 2018. Disponível em:

$<$ https://www.saude.gov.br/noticias/agencia-saude/43604-apesar-de-obesidade-em-alta-pesquisa-mostrabrasileiros-mais-saudaveis $>$. Acesso em: 17abr.2020.

INSTITUTO BRASILEIRO DE GEOGRAFIA E ESTATÍSTICA (IBGE). Censo Demográfico 2010. Rio de Janeiro: IBGE, 2010. Disponível em: https://biblioteca.ibge.gov.br/index.php/biblioteca-

catalogo?view=detalhes\&id=799. Acesso em: $24 \mathrm{mar} .2019$.

INSTITUTO BRASILEIRO DE GEOGRAFIA E ESTATÍSTICA (IBGE). Estatísticas do Registro Civil 2018. Rio de Janeiro: IBGE, 2018. Disponível em:

https://biblioteca.ibge.gov.br/visualizacao/periodicos/135/rc_2018_v45_informativo.pdf. Acesso em: $17 \mathrm{abr} .2020$.

MACIEL, Maria Regina Cazzaniga. Portadores de deficiência: a questão da inclusão social. São Paulo em Perspectiva, São Paulo, v.14, n.2, p.51-56, 2000. Disponível em:

$<$ http://www.scielo.br/scielo.php?pid=S0102-88392000000200008\&script=sci_arttext\&tlng=pt $>$. Acesso em: 01nov.2018.

MINOZZO, Marcele Cristiane; MARGHANI, Viviane Gaspar Ribas El. A acessibilidade do passageiro com necessidade de assistência especial: uma investigação em voo comercial no brasil. In: CONGRESSO BRASILEIRO DE PESQUISA E DESENVOLVIMENTO EM DESIGN, 12., 2016, Belo Horizonte. Proceedings [...] São Paulo: Blucher, 2016. v.9,n.2, p.3328-3340. Disponível em:

$<\mathrm{http}$ ://www.proceedings.blucher.com.br/article-details/a-acessibilidade-do- passageiro-com-necessidadede-assistncia-especial-uma-investigao-em-voo-comercial-no- brasil-24522>. Acesso em: 25jul.2018.

MORAES, M. C. Acessibilidade no Brasil: análise da NBR 9050. 2007. Dissertação (Mestrado em Arquitetura e Urbanismo) - Universidade Federal de Santa Catarina, Florianópolis, 2007.

OLIVEIRA, Thays Costa; ROSA, Maria Eduarda Ramos Cavalcanti. Desenvolvimento de uma fruteira para supermercados com base nos princípios ergonômicos e do Design Universal. In: CONGRESSO

BRASILEIRO DE PESQUISA E DESENVOLVIMENTO EM DESIGN, 13, 2018, Joinville. Anais [...]. Joinville: Univille, 2018.

ROSSI, Talita Naiara. Contribuições do entretenimento a bordo no conforto e desconforto em voos comerciais. 2011. Dissertação (Mestrado em Engenharia de Produção) - Universidade Federal de São Carlos, São Carlos, 2011. 
SANTOS, Sérgio Bernardo dos; FREITAS, Sydney Fernandes de. O "milagre" da multiplicação de assentos na classe econômica dos aviões comerciais. Ação Ergonômica, Rio de Janeiro, v.9, n.1, p.33-43, 2014.

Disponível em: <http://www.abergo.org.br/revista/index.php/ae/article/view/265>. Acesso em: 11mai2019.

SCHMID, Aloísio Leoni. Conforto como atmosfera: uma exploração da literatura sobre base da psicologia ambiental e da fenomenologia. Arquitextos, São Paulo, ano 18, n. 214.00, Vitruvius, mar. 2018. Disponível em: <https://www.vitruvius.com.br/revistas/read/arquitextos/18.214/6930>. Acesso em: 26jun.2019.

SOUZA, Jerusa Barbosa Guarda de. Acessibilidade em viagens de avião: o cenário regulatório e as necessidades das pessoas que demandam assistência especial. 2014. Tese (Doutorado em Engenharia de Produção) - Universidade Federal de São Carlos, São Carlos, 2014.

SOUZA, Jerusa Barbosa Guarda de. Parâmetros para o projeto de poltronas aeronáuticas: revisão da literatura e as práticas da indústria no setor de transportes. 2010. Dissertação (Mestrado em Engenharia de Produção) - Universidade Federal de São Carlos, São Carlos, 2010.

THE CENTER FOR UNIVERSAL DESIGN. The Principles of Universal Design. Raleigh: North Carolina State University, 1997. Disponível em:

$<$ https://projects.ncsu.edu/ncsu/design/cud/about_ud/udprinciplestext.htm> Acesso em: 18abr.2020.

WANDERLEY, Marcela L'Amour et al. Bases Comuns do Design: uma discussão sobre o impacto e papel social do design. In: ARRUDA, A. J. V. (org.). Design \& Complexidade. São Paulo: Blucher, 2017. cap.1, p.11-26.

WORLD HEALTH ORGANIZATION (WHO). Obesity: preventing and managing the global epidemic. WHO Technical Report Series, Geneva, v.894, 2000. Disponível em:

$<$ https://www.who.int/nutrition/publications/obesity/WHO_TRS_894/en/>. Acesso em: 30nov.2019. 